\title{
Preparation and Characterization of Melt Spun Polypropylene / Montmorillonite Nanocomposite Fibre for Ibuprofen Drug Delivery Application
}

\author{
Nadia H. Elsayed ${ }^{1,2}$, M. A. Alsharif ${ }^{1}$, W.S. Mohamed ${ }^{* 2}$ \\ ${ }^{1}$ Chemistry Department, Faculty of Science, University of Tabuk, Tabuk 71421, Saudi \\ Arabia ${ }^{2}$ Department of Polymers and Pigments, National Research Centre, Cairo \\ 12311, Egypt
}

\begin{abstract}
D OLYPROPYLENE /Montmorillonite clay nanocomposite was prepared after modification of Montmorillonite (MMT) clay using Dimethyl di (hydrogenated tallow) ammonium chloride modifier. The prepared nanocomposite was characterized using scanning electron microscope (SEM), Fourier-transform infrared (FTIR) and thermal gravimetric analysis (TGA). Fibers of pure polypropylene (PP) and polypropylene/montmorillonite clay nanocomposite (PP/MMT) were produced using melt spinning technique and the prepared fibers were characterized using mechanical properties, water absorption in addition to SEM analysis. The results show that the nanocomposite fibers have higher thermal stability, higher mechanical properties, and lower water absorption than pure polypropylene fibers in addition to high degree in homogeneity between polypropylene and MMT clay in polypropylene/montmorillonite nanocomposite. Ibuprofen drug (IBU) was successfully loaded into polypropylene and polypropylene/montmorillonite clay nanocomposite fiber via solvent immersion method with different drug fiber ratio in presence of glyoxal cross linker. Drug release profile was studied for $120 \mathrm{~min}$ and the results showed that about $33 \%$ from the initial loaded drug was released from the fiber after one hour of release starting time.
\end{abstract}

Keywords: Polypropylene, Montmorillonite, Melt Spinning, Drug Delivery, Ibuprofen.

\section{Introduction}

Polypropylene is one of the most polymers used in industry in the last decades [1]. It has great industrial applications due to its good characteristics including inexpensive, low density, chemical impedance and simple recycling [2]. The incorporation of nanoparticles into polymer enhances mainly physical, mechanical and barrier properties. Different synthesis and processing methods have been used in preparation of polymer / clay nanocomposites, relying on the type of polymer, type of clay in addition to the desired final structure. Generally, in-situ polymerization, melt intercalation and solution mixing are the common three methods for polymer nanocomposites preparation, where the first two methods considered the basic precursory strategies. The melt intercalation method has more economical and unpretentious than the in-situ polymerization method, however silicate layers full exfoliation is not constantly obtainable [3-4]. Giannelis et al [5] demonstrate melt intercalation and state that melt intercalation technique is considered a basic flow for the preparation of the intercalation polymer nanocomposite more than in-situ intercalative polymerization. From this time, universally extended research related to melt intercalation was executed. Now, development has been expanded including PA 6 [6], PP [7], and PET [8].

Recently, expanding consideration has been paid to nanofibers manufacturing by melt spinning techniques. Contrasted with micro scale fibers, nanofibers have a high surface area per unit volume that can accomplish more dynamic sites for industrial applications. Polypropylene fibers possess more interesting features than all synthetic fibers due to their high utilization in textile industry and other industrial fields[9-10]. Ibuprofen drug $\left(\mathrm{C}_{3} \mathrm{H}_{18} \mathrm{O}_{2}\right)$ is a hydrophobic white or almost white, crystalline powder or colorless crystals used as Cyclo-oxygenase inhibitor, analgesic and anti-inflammatory. It hinders the enzyme responsible for cyclooxygenase, which

\footnotetext{
*Corresponding author: Wael Sabry Mohamed

e-mail: wsabry1976@yahoo.com; ws.mohamed@nrc.sci.eg

DOI: 10.21608/EJCHEM.2018.2949.1244

C2017 National Information and Documentation Center (NIDOC)
} 
led to decrease in prostaglandins scales resulting in fever, pain and inflammation reduction[11]. The aim of this work is to prepare polypropylene /montmorillonite nanocomposite via melt extrusion process in order to produce melt spun poly propylene and polypropylene nanocomposite fibers for ibuprofen drug delivery application.

\section{Materials}

Montmorillonite clay (MMT) with cation exchange capacity (CEC) 100 meq per $100 \mathrm{~g}$ was supplied by Süd-Chemie - Moosburg -Germany.

The modifier Dimethyl di (hydrogenated tallow) ammonium chloride was supplied from Sigma -Aldrich - Steinheim - Germany.

Commercial homo-polymer polypropylene (HP561T) with melt flow rate (MFR) of $1.6 \mathrm{~g}$ / 10 min was supplied as a gift from DITF Denkendorf - Germany.

Glyoxal was purchased from Nen Tech Ltd. Brixworth Northants. U.K. Potassium dihydrogen phosphate $\left(\mathrm{KH}_{2} \mathrm{PO}_{4}\right)$ was purchased from GenLab (packaged in Egypt). Ethanol and sodium hydroxide were purchased from El-Nasr Company - Egypt. Ibuprofen was provided as a gift drugs from Smith Kline Glaxowelcome Company, Egypt.

\section{Methods}

Intercalated Modification of MMT with Dimethyl di(hydrogenated tallow) ammonium chloride [12].

MMT (2.5g) was dispersed into $250 \mathrm{ml}$ deionized water; the mixture was stirred for $1 \mathrm{~h}$ and then heated to $70^{\circ} \mathrm{C}$ to obtain aqueous suspension of clay. The desired amount of Dimethyl di(hydrogenated tallow) ammonium chloride ( $2 \mathrm{x}$ concentrations of the clay based on CEC) in $50 \mathrm{ml}$ deionized water was added into the mixture, the $\mathrm{pH}$ value of the solution was adjusted to 6-8 and stirring was continued for $4 \mathrm{~h}$. A white liberated precipitate was filtered and washed with deionized water. The obtained wet precipitate was dried under vacuum at $80{ }^{\circ} \mathrm{C}$ for $24 \mathrm{~h}$.

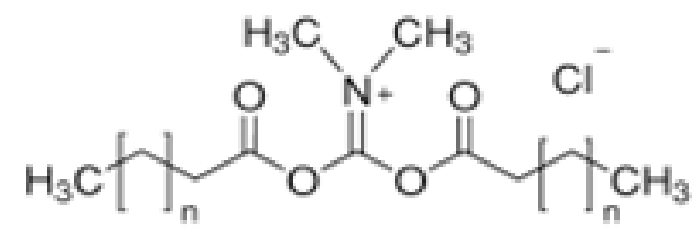

Fig. 1: Dimethyl di (hydrogenated tallow) ammonium chloride.

Egypt. J. Chem. 61, No.2 (2018)

\section{Preparation of Polypropylene / Montmorillonite Nanocomposite by Direct Melt Intercalation Method[13]}

Polymer melt-direct intercalation is an approach to make polypropylene/Montmorillonite nanocomposites using a conventional polymer extrusion process. Polypropylene was melt mixed with the modified MMT clay (1.0wt \%) using one litre reactor. The rotational speed $400 \mathrm{rpm}$ for 6 hours in order to have high shear stress and the temperatures of the reactor reached to $250^{\circ} \mathrm{C}$.

Polypropylene / Montmorillonite Fibre Production via Melt Spinning Method[13]

Before the fibre production, the polypropylene /montmorillonite nanocomposite was dried at 0.1 bar and $160^{\circ} \mathrm{C}$. Continuous fibres were produced via spinning process using extruder Haake 9000 (Germany). The solid polymeric pellets were introduced in the spinning machine which has three independent temperature areas and is equipped with a pressure sensor. In order to process the $\mathrm{PP} / \mathrm{MMT}$ clay nanocomposite filament, the heating temperature is regulated between 180 and $230{ }^{\circ} \mathrm{C}$. As a spinning pump a toothed wheel pump (or gear pump) is available, whose delivery volume is $0.6 \mathrm{~cm} 3$. The control of the temperature at the pump and the spinneret is affected by a thermal element where a spinning nozzle a 10-hole-spinneret (diameter of pore $200 \mu \mathrm{m}$ ) is used after turning the spinning-fiber around two galettes, it is spooled on a coil by a coiler (winder) from Barmag, Type SW 66 SSD.

\section{Water Absorption}

The Water absorption test was based on immersion of fibers onto water for different interval time (30min, $60 \mathrm{~min}$ and $120 \mathrm{~min}$ ) at room temperature. Water absorption percentage (S \%) was determined from the following equation.

$$
\mathrm{S} \%=\left(\mathrm{M}-\mathrm{M}_{0} / \mathrm{M}_{0}\right) \times 100
$$

Where $\mathrm{M}$ is the mass of the swollen PP fibres in distilled water at room temperature and $\mathrm{M}_{0}$ is the mass of the same PP fibres dried at $50{ }^{\circ} \mathrm{C}$.

Ibuprofen drug loading into polypropylene and polypropylene nanocomposite fibres using solvent immersion method[14].

Ibuprofen drug (Fig. 2) loading was done using a solvent immersion method by dissolving ibuprofen drug in ethanol $(200 \mathrm{mg} / \mathrm{ml})$ then; different amount of polypropylene or polypropylene nanocomposite fibre samples added to the solution in presence of glyoxal cross linker in absence of light. The mixture 
was brought to equilibrium overnight under gentle stirring in closed container using magnetic stirrer then, filtered by vacuum filtration using a Büchner funnel with the filter flask attached to a water aspirator.<smiles>CC(C)Cc1ccc(C(C)C(=O)O)cc1</smiles>

Fig. 2: Ibuprofen drug formula.

\section{Drug entrapment efficiency (EE\%)}

To determine the drug entrapment efficiency (EE \%) loaded onto the fibre, measuring the free drug (unloaded drug). The initial drug concentration and the drug concentration in the solution after finishing the immersion process was determined by measuring the absorbance at $263 \mathrm{~nm}$ on a Shimadzu Ultraviolet-visible spectrophotometer with double beam using a standard calibration curve experimentally obtained with methanol solutions.

The drug EE was defined as the ratio of the weight of the drug loaded into the spinning fiber to the weight of the drug initially used[15].

The weight of the drug loaded into the spinning fiber

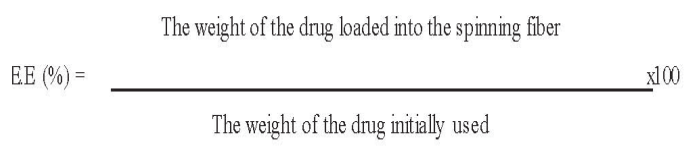

\section{In-Vitro release of Ibuprofen [16]}

In this study, the effects of the ratio of the drug to fiber carriers on the in vitro release of ibuprofen (IBU), loaded fiber was evaluated.

After the solvent immersion process, the drug loaded carrier fibres were collected using a rotary evaporator. In comparison with the other drying methods, the utilization of rotary evaporation in the loading process has shown significant advantages, such as process simplification by avoiding filtration to reduce the risk of crystallization of the drug on the surface of the carriers, fixing amounts of the loaded drug and providing industrial scalability for loading the drug into the fibres.

The Ibuprofen drug releases from the drugloaded fibres at different loading conditions were performed in a phosphate buffered saline media of pH 7.4 using a dialysis bag technique. Buffer solution of $\mathrm{pH} 7.4$ was prepared by mixing $250 \mathrm{ml}$ of $0.1 \mathrm{M} \mathrm{KH}_{2} \mathrm{PO}_{4}$ and $195.5 \mathrm{ml}$ of $0.1 \mathrm{M}$ $\mathrm{NaOH}$. Dialysis sacs were equilibrated with the dissolution medium for few hours before experiments.

\section{Characterization}

X-ray diffraction (XRD) measurements were performed using a Philips powder-diffractogram PW 1050 with ADM software and with Ni-filtered $\mathrm{Cu}-\mathrm{K}$ radiation. The accelerating voltage was $40 \mathrm{KV}$, and the current was $30 \mathrm{~mA}$.

The morphology and fracture surface of the polymer and its composite were examined by scanning electron microscope (SEM) analysis using a Zeiss DSM 962 microscope.

The amount of free drug and drug released were determined by using the ultraviolet-visible recording spectrophotometer (Cary 500, Varian) equipped with a quartz cell having a path length of $1 \mathrm{~cm}$ at $\lambda$-max $210 \mathrm{~nm}$.

Thermogravimetric analysis (TGA) was determined on a TGA 7 thermogravimetric analyzer (Perkin Elmer) under a nitrogen flow at a heating rate of $10 \mathrm{oC}$ min- 1 . The Fourier transfer infrared (FTIR) spectra were obtained using a Bruker IFS 28 spectrometer 67.

The mechanical properties of the polypropylene fibers were measured with a Zwich Zugprufgerat machine (Ulm, Germany) with a force of $10 \mathrm{KN}$. (ASTM D-3822-07)

\section{$\underline{\text { Results and Discussions }}$}

\section{Modification of MMT clay}

Figure 3 illustrates X-ray diffraction for pristine MMT clay and its intercalated modified MMT using Dimethyl di (hydrogenated tallow) ammonium chloride. The interlayer spacing $\left(\mathrm{d}_{001}\right)$ value of the pristine and modified MMT are calculated via Bragg's equation:

$$
\mathbf{n} \lambda=\mathbf{2} \mathbf{d} \sin \theta
$$

From the figure, it is clear that, due to the shifting in diffraction peak position of the pristine clay to a smaller value, intercalation modification of MMT successfully occurred. Where, the figure

Egypt. J. Chem. 61, No.2 (2018) 


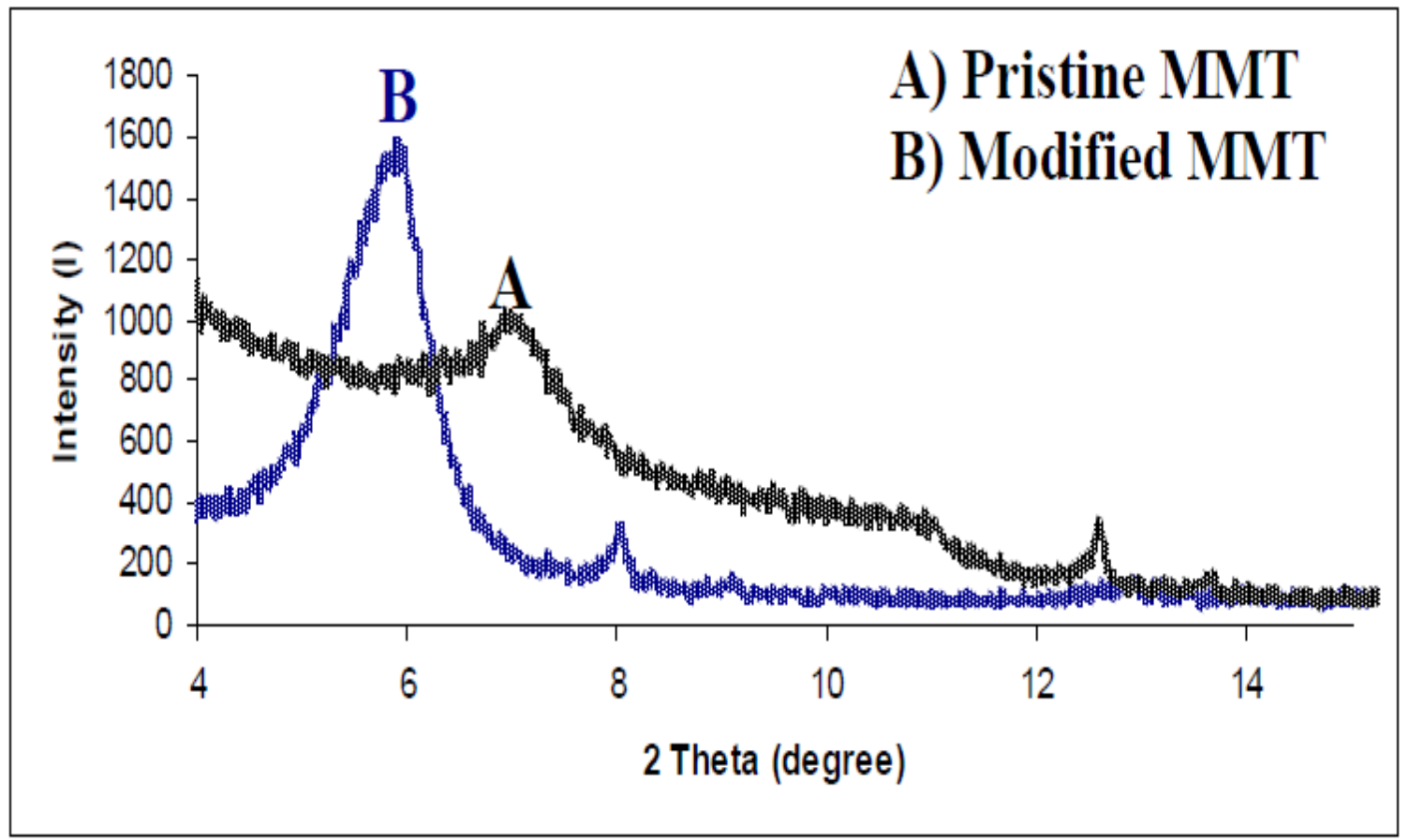

Fig. 3: XRD pattern for A) pristine MMT and B) Modified MMT clay.

shows that that, the diffraction peak position of the MMT shifted from $2 \theta$ value $6.98{ }^{\circ} \mathrm{C}$ to 5.92 ${ }^{\circ} \mathrm{C}$ which means that, there is an increment in d-spacing of the MMT clay from 11.7 to $13.8 \mathrm{~nm}$.

\section{Preparation of Polypropylene / Montmorillonite}
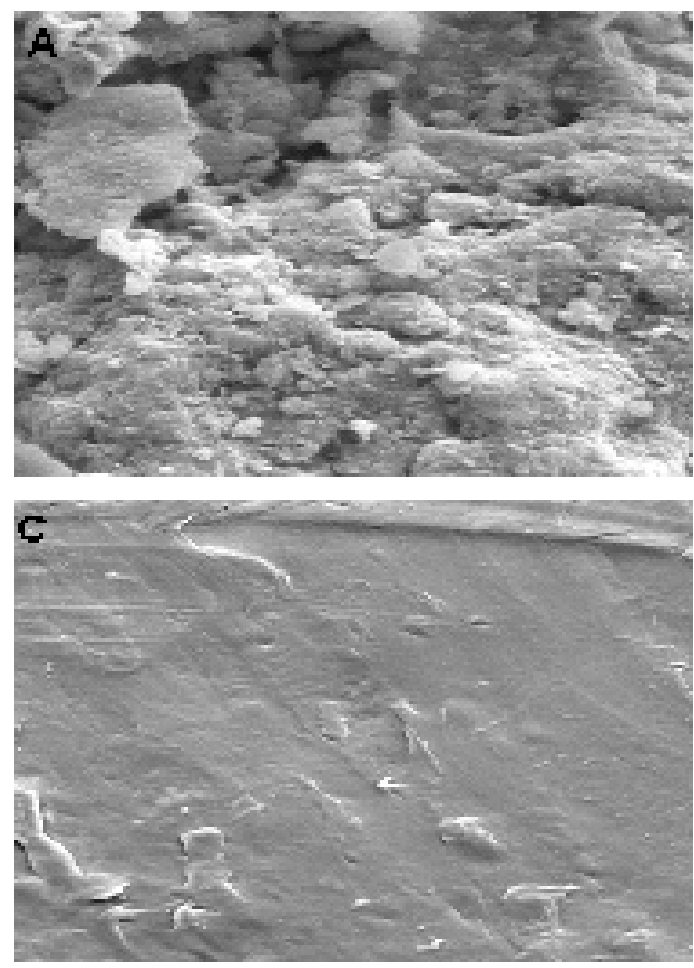

Nanocomposite

Scanning Electron Microscope

The morphology investigation of pristine MMT, modified MMT, pure PP and PP/ modified MMT nanocomposite prepared by direct melt intercalation method is achieved by scanning
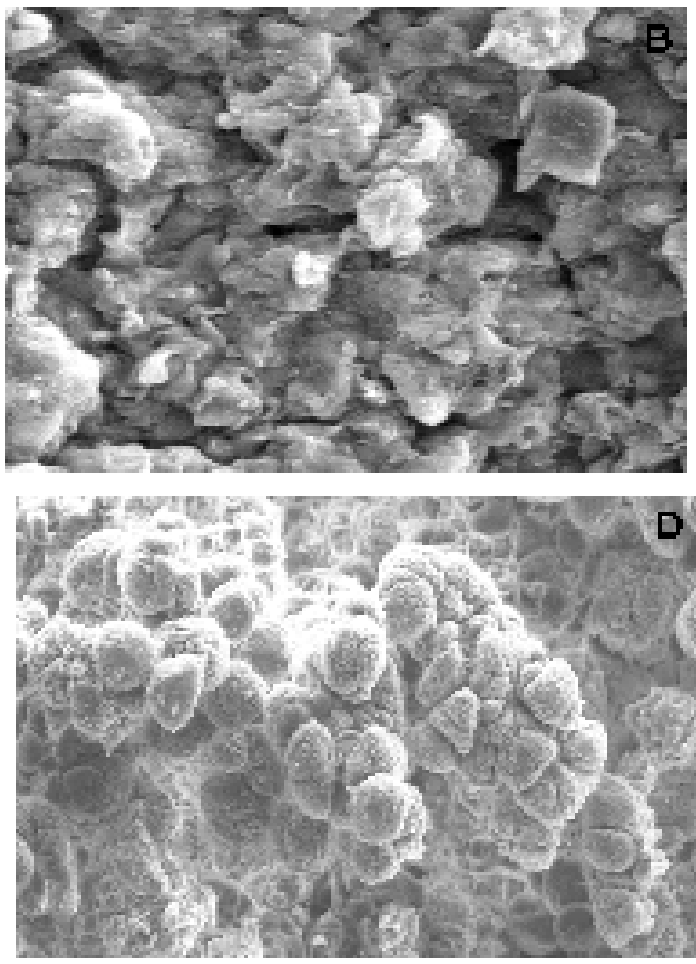

Fig. 4. SEM of A) Pure MMT, B) Modified MMT, C) Pure PP and D) PP/Modified MMT nanocomposite Egypt. J. Chem. 61, No.2 (2018) 
electron microscope (SEM) (X500) and is present in Fig. 4.

After MMT modification and in order to investigate the effect of modification, both pristine MMT and modified MMT were dispersed from water and examined using SEM analysis.

Agglomeration morphology of pristine MMT clay due to its poor dispersion is noticeable in SEM of pristine MMT, where, a good dispersion of modified MMT clay leads to its uniform distribution due to an effective organophilic transformation of the modified MMT clay.

A uniformly homogenous dispersion of the modified clay without agglomeration is observed in the PP matrix which is considered an indication of the successful preparation of the PP/MMT nanocomposite.

Figure 5 represents FTIR of pure PP, modified-MMT (M-MMT) and PP / 1\% M-MMT nanocomposites. The figure showed the appearance of $\mathrm{Si}-\mathrm{O}$ group characteristic absorption band at $1092 \mathrm{~cm}^{-1}$ [17] in both modified-MMT clay and temperature in which the fibre loses $75 \%$ of its weight $\left(\mathrm{T}_{75}\right)$. The determined temperatures are listed in Table 1.

From the table, it is clear that, $\mathrm{T}_{25}, \mathrm{~T}_{50}$ and $\mathrm{T}_{75}$ temperature have high values in case of $\mathrm{PP} /$ MMT than in case of pure PP due to the motion limitation of MMT clay layers [13].

TABLE 1: TGA data obtained for pure PP and PP/ MMT nanocomposite

\begin{tabular}{ccc}
\cline { 2 - 3 } & Pure PP & PP/modified MMT \\
\hline $\mathrm{T}_{\text {Start }}$ & 130 & 148 \\
$\mathrm{~T}_{25}$ & 192 & 212 \\
$\mathrm{~T}_{50}$ & 220 & 237 \\
$\mathrm{~T}_{75}$ & 244 & 263 \\
\hline
\end{tabular}

Polypropylene / Montmorillonite Fibre Production

Modified MMT incorporation into the PP fiber through PP melt spinning is mainly carried out for enhancement the PP fiber properties.

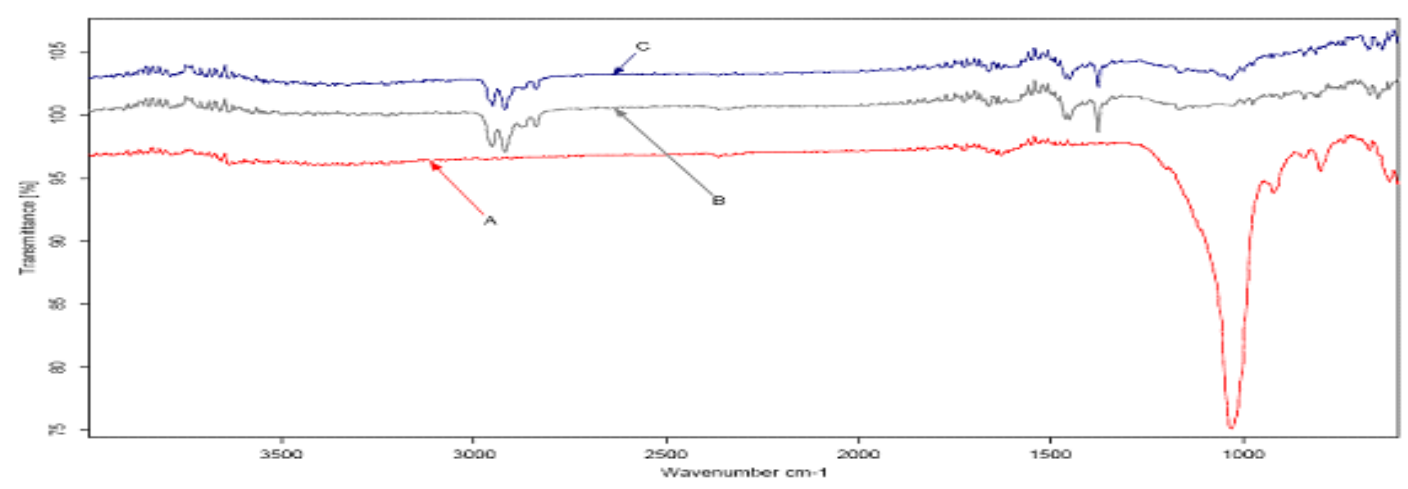

Fig. 5. FTIR spectrum of A) Modified-MMT, B) Pure PP and C) PP/ modified-MMT nanocomposite

PP/MMT nanocomposite patterns indicates the successfully preparation of PP / modified MMT nanocomposites.

\section{Thermal Gravimetric Analysis}

Thermal gravimetric analysis (TGA) for both polypropylene and polypropylene clay nanocomposite in temperature range between 50 $600{ }^{\circ} \mathrm{C}$ is represented in Fig. 6 .

This figure is used in determining of the following temperatures, i) the fibre starting degradation temperature (Tstart), ii) the temperature in which the fibre loses $25 \%$ of its weight $\left(\mathrm{T}_{25}\right)$, iii) the temperature in which the fibre loses $50 \%$ of its weight $\left(\mathrm{T}_{50}\right)$ and iv) the

\section{Mechanical Properties}

The mechanical properties were investigated for both pure PP and PP/MMT nanocomposite fibre in order to elucidate the MMT addition effect on mechanical properties of polypropylene fibre including tensile and elongation parameters (T.S, $\mathrm{E}$ and $\left.\mathrm{E}^{*}\right)$. The data obtained from mechanical properties investigation listed in Table 2. This data refers to an increment in the fibre mechanical properties as a result of modified MMT addition which indicate better dispersion of MMT in the PP fibre.

\section{Water Absorption}

Water absorption for pure PP and PP/MMT nanocomposite fibres was calculated through

Egypt. J. Chem. 61, No.2 (2018) 
different time intervals. The data obtained from water resistance calculation are listed in Table 2. Where the results indicate that, pure PP/MMT nanocomposite fibre has to be less resistance to water absorption in comparison with pure PP fibre which indicate that MMT clay is useful for enhancement the polypropylene fibre water repellence.

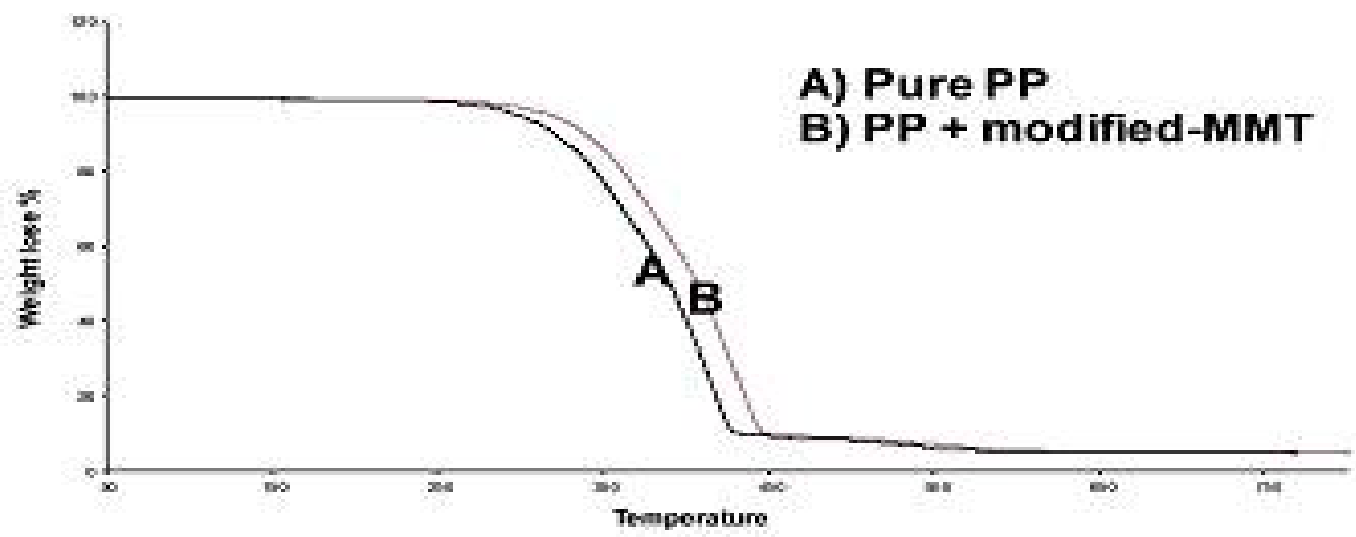

Fig. 6. TGA thermograms of pure PP and the PP/MMT nanocomposites.

TABLE 2: Mechanical properties and water absorption of pure PP and PP/MMT nanocomposite fibres

\begin{tabular}{ccccccc}
\hline \multirow{2}{*}{ Sample } & \multicolumn{3}{c}{ Mechanical properties } & \multicolumn{2}{c}{ Water absorption (\%) } \\
\cline { 2 - 6 } & $\begin{array}{c}\text { Tensile } \\
\text { Strength in } \\
\text { MPa } \\
\text { (T.S) }\end{array}$ & $\begin{array}{c}\text { Elongation at } \\
\text { break } \\
(\mathbf{E})\end{array}$ & $\begin{array}{c}\text { Elongation at } \\
\text { Fmax } \\
\left(\mathbf{E}^{*}\right)\end{array}$ & $\mathbf{3 0}$ min. & $\mathbf{6 0} \mathbf{m i n .}$ & $\mathbf{1 2 0}$ min. \\
\hline Pure PP fibre & 143.9 & 25.3 & 26.3 & 107.5 & 128.0 & 147.3 \\
\hline PP/MMT fibre & 164.5 & 25.5 & 26.6 & 100.3 & 107.5 & 123.2 \\
\hline
\end{tabular}
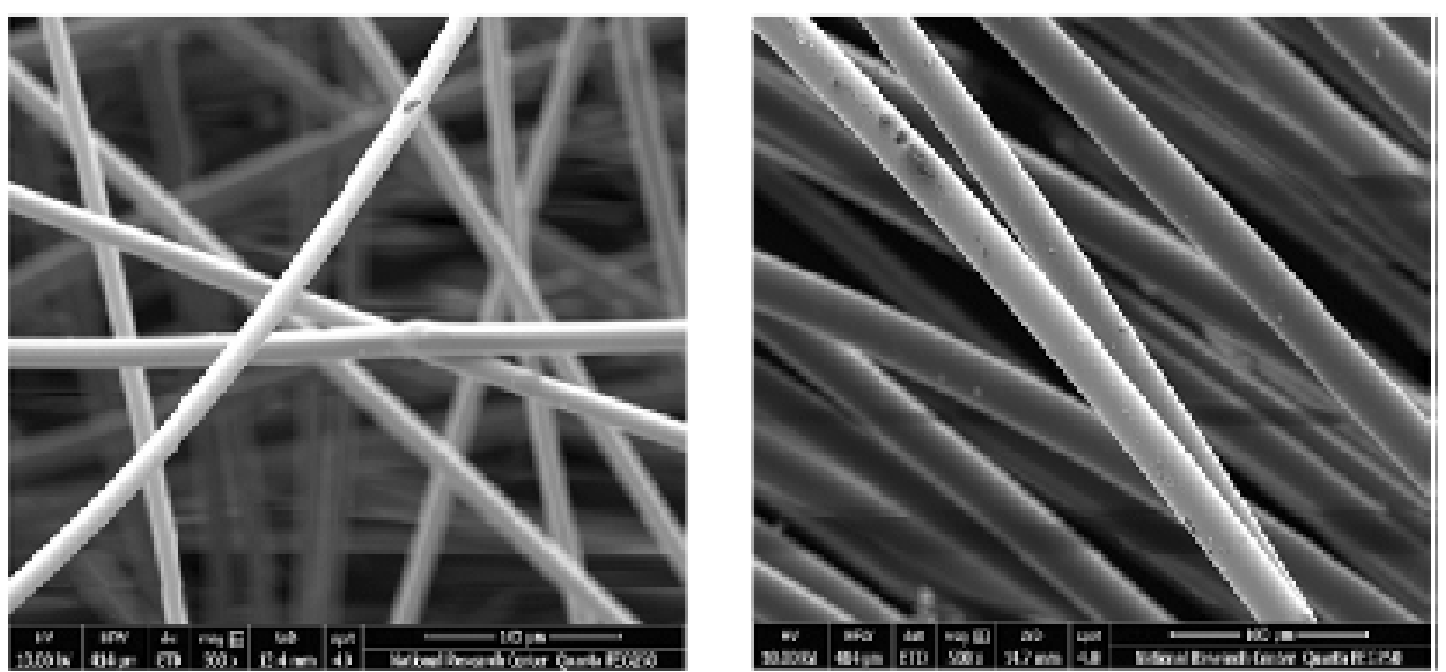

Fig. 7: SEM of A) pure PP and B) PP/MMT fibres.

Egypt. J. Chem. 61, No.2 (2018) 
Scanning Electron Microscope (SEM)

Morphology investigation for both pure PP and PP/MMT nanocomposite fibers was illustrated by SEM analysis and represented in Fig.7.

The SEM analysis shows the smooth of pure PP fibers represents the high degree in homogeneity between the PP fibre and MMT clay which indicates the successful preparation of PP / modified MMT nanocomposites[18].

\section{Ibuprofen drug loading}

A certain weight of both PP and PP/MMT spinning fibre are immersed in ibuprofen drug in ethanol solution $(200 \mathrm{mg} / \mathrm{ml})$ in presence of $5 \%$ glyoxal for 60 min under shaking. Effect of drug / fibre concentration ratio and time of fibre immersion was studied.

TABLE 3: Entrapment efficiency \% of Ibuprofen drug loading into PP and PP/MMT spinning fibres using different drug/fibre ratios.

\begin{tabular}{|c|c|c|}
\hline \multirow[b]{2}{*}{ Drug/fiber ratio } & \multicolumn{2}{|c|}{$\mathrm{EE} \%$} \\
\hline & Pure PP fiber & $\mathrm{PP} / \mathrm{MMT}$ fiber \\
\hline $1: 1$ & 19.7 & 32.3 \\
\hline $1: 2$ & 15.4 & 28.5 \\
\hline $1: 3$ & 12.4 & 30.2 \\
\hline
\end{tabular}

The high surface area of MMT and increasing Van der Walls forces led to enhancement of drug adsorption in case of PP/MMT spinning fibre [20].

\section{Effect of time of fibre immersion}

Ibuprofen drug / fibre ratio 1:1 using PP/ MMT spinning fibre was immersed in ethanol solution in presence of glyoxal cross linker for different time intervals and the E.E \% was calculated for each time interval. The result data listed is table 4. From the data, it can be concluded that, the drug adsorption is very rapidly at first interval and reached maximum after $60 \mathrm{~min}$ then it remains constant.

\section{Effect of drug / fibre concentration:}

Three different drug / fibre concentration ratio which are 1:1, 1:2 and 1:3 was studied and the drug entrapment efficiency was determined for each ratio by determining the drug concentration in the solution after finishing the fibre immersion process.

Entrapment efficiency (E.E) \% was calculated for each ratio and the data are recorded in Table 3. From the recorded data, it was concluded that, E.E $\%$ is inversely proportional with the fibre ratio in both spinning fibres used. From the data, it is also clear that E.E \% for the PP/MMT nanocomposite fibre is higher than that of the pure PP fibre due to presence of MMT clay which increases the available active sites for drug adsorption[19].
Ibuprofen drug release profile

Figure 8 represents the Ibuprofen release profile from drug loaded PP/MMT spinning fiber with fiber/drug ratio 1:1 after $60 \mathrm{~min}$ drug loading time. During $120 \mathrm{~min}$ releasing time, rapid initial drug release was observed for the first $30 \mathrm{~min}$ and reached to about $23 \%$ from the initial loaded drug, then the release rate decreased in the next $30 \mathrm{~min}$ till reached to plateau region after one hour of release starting time [21] where the total release reached to about $33 \%$ from the initial loading drug.

TABLE 4: Entrapment efficiency (EE) \% of Ibuprofen drug loaded on PP/MMT spinning fibres using drug/fibre ratio 1:1 in different time of fibre immersion.

\begin{tabular}{|c|c|c|c|c|c|c|}
\hline & \multicolumn{6}{|c|}{ Time of fibre immersion } \\
\hline & $15 \mathrm{~min}$ & $30 \mathrm{~min}$ & $45 \mathrm{~min}$ & $60 \mathrm{~min}$ & $90 \mathrm{~min}$ & $120 \mathrm{~min}$ \\
\hline E.E \% & 12.8 & 17.6 & 29.5 & 32.3 & 32.1 & 32.1 \\
\hline
\end{tabular}




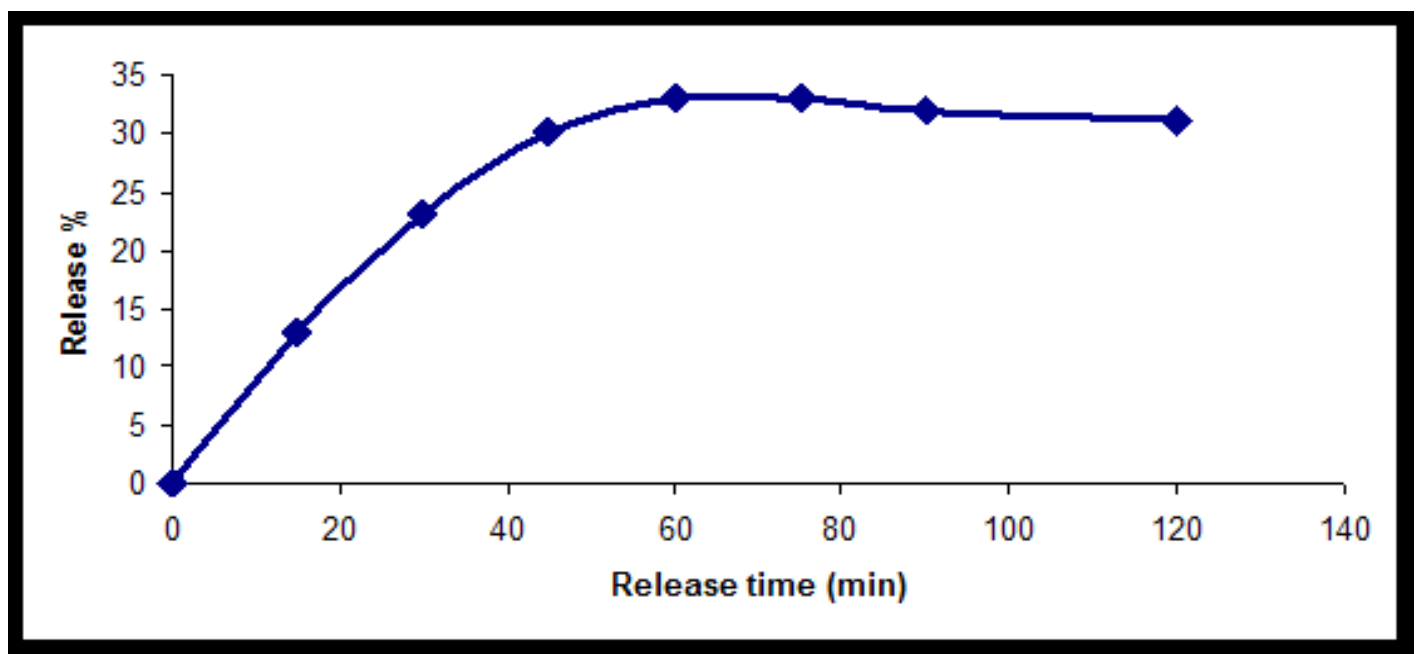

Fig. 8 : Ibuprofen release profile from drug loaded PP/MMT spinning fiber with fiber/drug ratio 1:1 after $60 \mathrm{~min}$ drug loading time.

\section{Conclusion}

Polypropylene (PP) / Montmorillonite (MMT) nanocomposite was prepared after modification of MMT clay using Dimethyl di(hydrogenated tallow) ammonium chloride modifier.

The prepared nanocomposite was characterized using SEM, FTIR and TGA analysis where the appearance of $\mathrm{Si}-\mathrm{O}$ group characteristic absorption band at $1092 \mathrm{~cm}-1$ in both modifiedMMT clay and PP/MMT nanocomposite patterns, all degradation temperature have high values in case of PP/MMT than in case of pure PP due to the motion limitation of MMT clay layers and a uniformly homogenous dispersion of the modified clay without agglomeration which is observed in the PP matrix confirm the successful preparation of the PP/MMT nanocomposite 15.

Pure PP and PP/MMT nanocomposite fibres were produced using melt spinning technique and the prepared fibers were characterized using mechanical properities, water absorption in addition to SEM analysis which confirm the benefits of MMT addition in the enhancement of PP fiber properties.

Ibuprofen drug was successfully loaded into the PP and PP/MMT fibers via a solvent immersion method with different drug / fiber ratio in presence of glyoxal cross linker. The results showed that, E.E \% for the PP/MMT nanocomposite fibre is higher than that of the pure PP fibre due to presence of MMT clay and reached to $32.3 \%$ for drug/fiber ratio 1:1 during an hour immersion time.
Ibuprofen release profile from drug loaded PP/MMT spinning fiber with fiber/drug ratio 1:1 after 60 min drug loading time was studied and the results showed that about $33 \%$ from the initial loaded drug was released from the fiber after one hour of release starting time.

\section{Acknowledgment}

The author would like to acknowledge University of Tabuk for the financial support under research project number S1438-0030.

\section{References}

1. Singh K.,Nanda T. and Rajeev M. Processing of polyethylene terephthalate fiber reinforcement to improve compatibility with constituents of GFRP nanocomposites. Materials and Manufacturing Processes, 33(2), 1-9(2018).

2. Seok K. and Soo-Jint P. Interlayer spacing effect of alkylammonium-modified montmorillonite on conducting and mechanical behaviors of polymer composite electrolytes. Journal of Colloid and Interface Science, 332, 145-150 (2009).

3. Blaznov A.N., Atyasova E.V., Shundrina I.K. and Zubkof A.S. Thermomechanical characterization of BFRP and GFRP with different degree of conversion. Polymer Testing., 60,49- 57(2017).

4. $\mathrm{Hu}$ D., Chen J. and Liu T. Melting and non-isothermal crystallization behaviors of polypropylene and polypropylene/ montmorillonite nanocomposites under 
pressurized carbon dioxide, Thermochimica Acta, 617, 65-75(2015).

5. Viaa, R. A., Ishii, H. and Giannelis, E. P. Synthesis and properties of twodimensional nanostructures by direct intercalation of polymer melts in layered silicates, Chem. Master. 5, 103-116 (1993).

6. Mohamed, W.S., Nasr, H.E., Gutmann, R. and Sobh, R. A. Study the Ultrasonic Assisted For Polymeric Nanocomposite, Egyption Journal of Chemistry, 60, 109-128 (2016).

7. Jungang, G., Xinxin, C., Chong, Z. and Wentao, H. Non-isothermal crystallization kinetics of polypropylene/MAP-POSS nanocomposites, Polymer Bulletin, 70,1977- 1990 (2013).

8. Tomisawa R, Ikaga T, Kim K.H, Okhoshi Y, Okada Y, Masoung H, Kanaya T, Masuda M and Maeda Y. Efeect of melt spinning conditions on the fiber structure development of polyethylene terphthalate, Polymer,116, 367-377 (2017).

9. Silvestre, C., Pezzuto, M., Duraccio, D., Mitchell, G.R. and Cimmino, S. Quiscent and shearinduced non-isothermal crystalization of isotactic polypropylene based nanocomposite, Polymer Bulletin, 74,145-165 (2017).

10. Slavutsky,A.M. andBertuzzi, M.A. Thermodynamic study of water sorptionand water barrier properties of nanocomposite films based on brea gum, Applied Clay Science, 108,144-148(2015).

11. Moustafa, A. B., Sobh, R. A., Rabie, A. M., Nasr, H.E. and Ayoub M. Synthesis and in vitro release of guest drugs-loaded copolymer nanospheres MMA/HEMA via differential microemulsion polymerization, Journal of Applied Polymer Science, 129, 853-865(2013).

12. Effenberger, F., Schweizer, M. and Mohamed,WS. Synthesis and characterization of some polyacrylate/montmorillonite nanocomposites by in situ emulsion polymerization using redox initiation system, Journal of Applied Polymer Science, 112, 1572-1578 (2009).

13. Effenberger, F., Schweizer, M. and Mohamed, WS. Effect of Montmorillonite Clay Nanoparticles on the Properties of Polypropylene Fibres. PolymerPlastics Technology and Engineering, 49, 525 530(2010).

14. Abdel-Bary, A., EL-Nabarawi, M. A., Hassen, D. H. and Taha, A. A. Ketoprofen mesoporous silica nanoparticles SBA-15 hard gelatin capsules: preparation and in vitro/in vivo characterization. Drug Delivery, 23, 3387-3398 (2016).

15. Moustafa, A. B., Sobh, R. A., Rabie, A. M., Nasr, H.E. and Ayoub, M. Differential microemulsion polymerization as a new root for entrapment of drugs, Journal of Applied Polymer Science, 127, 4634- 4643 (2013).

16. Lai, J., Lin, W., Scholes, P. and Li, M. Investigating the Effects of Loading Factors on the In Vitro Pharmaceutical Performance of Mesoporous Materials as Drug Carriers for Ibuprofen. Materials, 10,150,1-15(2017).

17. Verrey J., Wakema, M.D., Michaud, V. and Manson, J.A.E. Strain rate effect on interlaminar shear strength of carbon fibre reinforced $\mathrm{pCBT}$ and epoxy, Composites, 37, 9-22(2006).

18. Asim D. Production of POSS nanoparticle containing polypropylene fibres dyeable with acid and basic dyes. Indian Journal of Fibre \& Textile Research, 42, 209 -214 (2017).

19. El-Feky G. S., Sharaf S. S., El Shafei A. and Hegazy A. A. Using chitosan nanoparticles as drug carriers for the development of a silver sulfadiazine wound dressing, Carbohydrate. Polymers, 158, 11 19 (2017).

20. Lee D., J. Lee S. and Kim W.I. Effects of humidity and surfaces on the melt crystallization of ibuprofen, International Journal of Molecular Sciences, 13, 10296 - 10304 (2012).

21. Anderson N. H., Bauer M., Boussac N., KhanMalek, Munden P. and Sardaro M. An evaluation of fit factors and dissolution efficiency for the comparison of in vitro dissolution profiles, Journal of Pharmaceutical and Biomedical Analysis, 17, 811- 822(1998)

(Received 18/2/2108; accepted 14/3/2018) 
تحضير وتوصيف ألياف متر اكب البولى بُروبيلين مع طقلة المونتموريلونيت بطريقة الغزل

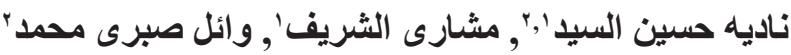

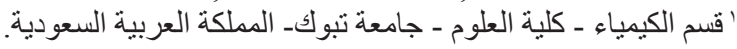

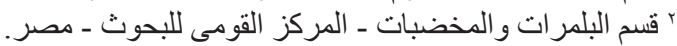

تم تحضير متر اكب البولى بروبيلين مع طفلة المونتموريلونيت بعد تعديلها بإنتخدام أملاح الأمونيوم. كما تم المباء

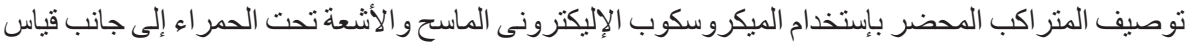
مدى الثبات الحر ارى بإستخدام التحليل الحر ارى الوزنى.

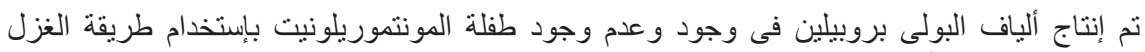

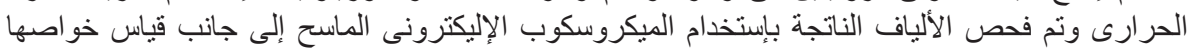

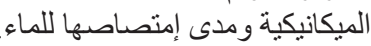

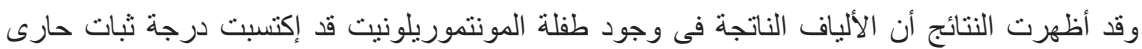

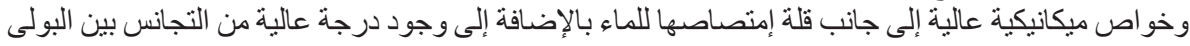

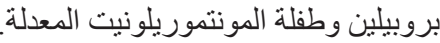

تم إستخدام طريقة الغمر فى تحميل عقار الإيبوبروفين على ألياف البولى بروبلين الدحتوية على طفلة

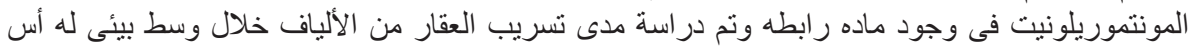

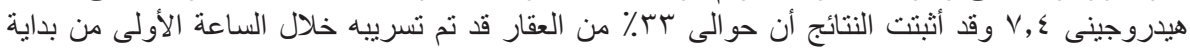

